\title{
OCCURRENCE OF ENDOPARASITES IN INDIGENOUS ZAMBIAN DOGS
}

\author{
Bruce-Miller, M., Goldová, M. \\ Institute of Parasitology, University of Veterinary Medicine and Pharmacy \\ Komenského 73, 041 81, Košice \\ The Slovak Republic \\ maria.goldova@uvlf.sk
}

\section{ABSTRACT}

This study was conducted in the country of Zambia, Southern Africa, to investigate the occurrence of endoparasites in indigenous Zambian dogs. Faecal samples were collected from 41 indigenous Zambian dogs from different areas of the Mbabala region in the Southern province of Zambia during the "hot wet" season, although at the time that the samples were collected, the country was experiencing a drought. Faecal samples were analysed using the concentration flotation method with zinc sulphate for the determination of the presence of gastrointestinal parasites. The most prevalent parasites were species from the family Ancylostomatidae (65.0\% infection rate) which followed by: Isospora canis (9.8\%), Dipylidium caninum (4.8\%), and Toxascaris leonina $(2.4 \%)$. There were in addition, two cases of co-infections with the family Ancylostomatidae and D.caninum, as well as the family Ancylostomatidae and I. canis.

Key words: dog; endoparasite; family Ancylostomatidae; Toxascaris leonina; Dipylidium caninum; Isospora canis

\section{INTRODUCTION}

Parasitism is the most prevalent canine disease worldwide, negatively impacting not only its canine host [11] but also humans due to their potential to act as a zoonotic reservoir [3, 7]. In the large rural areas of Zambia, it is common to find a large population of malnourished freeranging dogs. This situation combined with a general lack of animal welfare education, poor veterinary services and widespread poverty in the rural regions, exacerbates this health risk significantly [7].

The aim of this study was to investigate the occurrence of endoparasites in indigenous Zambian dogs. This constitutes the first study of its kind being conducted in this region.

\section{MATERIALS AND METHODS}

This study was conducted in Zambia, a Southern Africa country located between $22^{\circ}$ and $34^{\circ}$ East and $8^{\circ}$ and $18^{\circ}$ South (Fig. 1). Specifically, it took place in the Southern 


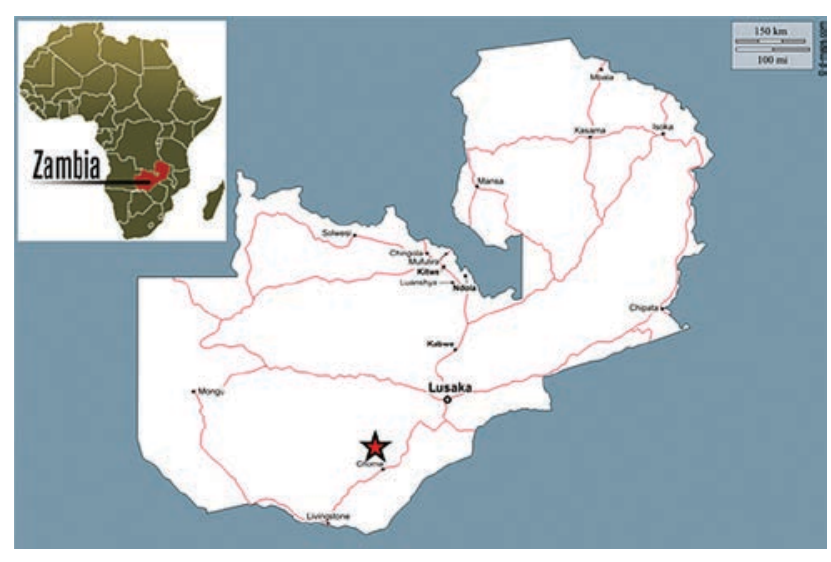

Fig. 1. Zambia, geographical location of the sampling region is indicated by the star [2]

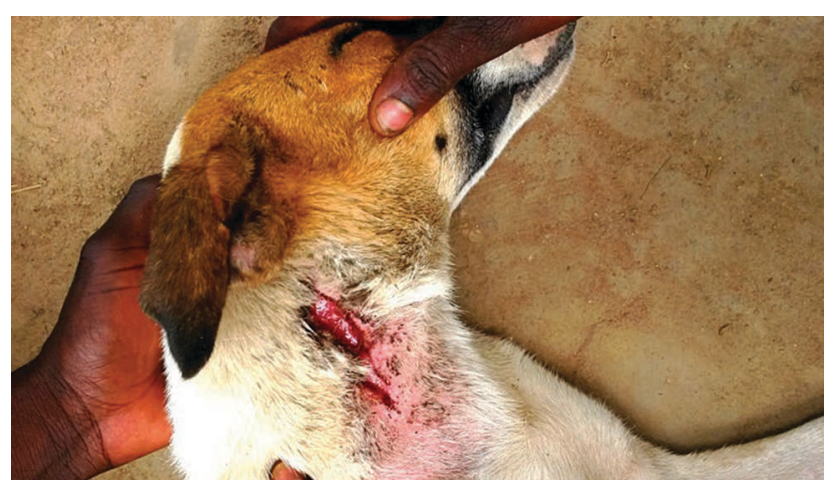

Fig. 2. A gash from an encounter with a baboon (Original photo) province of Zambia in the rural villages near the Mbabala town of Choma district [2].

Zambia has a subtropical climate with 3 distinct seasons: The "cool dry" season which is the winter equivalent (between May and July) with mean daily temperatures falling between 15 and $27^{\circ} \mathrm{C}$, followed by the "hot dry" season (from August to October) with temperatures peaking at $27-32^{\circ} \mathrm{C}[5]$.

Samples were obtained and analysed during the "hot wet" season (known as "the rainy season") as $95 \%$ of the annual precipitation occurs during these months. It runs from November to April ( $803 \mathrm{~mm}$ of rain on average yearly) [9], however at the time of our sampling, the country was experiencing a drought.

Individuals that owned one or two dogs used in this study tended to be keeping them for companionship and personal security. However, there were two cases where larger packs of up to 6 dogs were owned to protect crops from animals such as baboons and for hunting - both legal and illegal (Fig. 2). There were also a few statements made that the dogs were occasionally a source of income by selling them to the Chinese quarry team located nearby. The dogs were all kept outside and very rarely allowed in the house beyond the veranda. Very few had visited the local veterinarian; for those that had received veterinary attention it was for rabies vaccination. No dogs had been given therapeutic or prophylactic worming medication due to a lack of education, widespread poverty and their isolated location. Upon receiving the information from the owner that the dogs had never been treated for endoparasites they were given free deworming medication as a re- ward for their cooperation with this study. On the whole, all dogs surveyed were in poor condition, malnourished with evidence of ectoparasites (fleas and ticks), scars and occasionally obvious sores that warranted immediate medical attention. They were not receiving any veterinary assistance due to their rural location and the veterinary bill being beyond the reach of their income.

All samples were collected and analysed in the Southern province of Zambia from 28 different owners in 3 separate villages. Faecal samples were all taken per rectum with a lubricated gloved hand. The faeces were contained in a double glove and immediately placed in a cool box with ice packs. Each sample was assigned a number and further details recorded such as name of the dog and owner, as well as their specific location, size of the dog, breed, sex, age, reason for ownership, body condition and veterinary treatment history. Later, the samples were transferred into a third plastic bag and kept in the refrigerator at $4^{\circ} \mathrm{C}$ for a maximum of 5 days.

The samples were later subjected to the concentration flotation method with zinc sulphate and analysed under a microscope where eggs/oocysts were identified and the intensity of the infection was gauged as follows: low (one egg per drop), medium (10 eggs per drop), high (5 eggs per $20 \times$ magnification field) [6].

\section{RESULTS}

The parasites found in the coprological examination included helminth eggs of the family Ancylostomatidae, Dipylidium caninum, and Toxascaris leonina, as well as oo- 
Table 1. Adult dogs with overall species prevalence and prevalence per sex

\begin{tabular}{lccc}
\hline \multicolumn{1}{c}{ Species } & $\begin{array}{c}\text { Prevalence }- \text { total } \\
{[\%]}\end{array}$ & $\begin{array}{c}\text { Male } \\
{[\%]}\end{array}$ & $\begin{array}{c}\text { Female } \\
{[\%]}\end{array}$ \\
\hline Family Ancylostomatidae & $21(67.7)$ & $10(71.4)$ & $11(64.7)$ \\
Isospora canis & $3(9.7)$ & $2(14.3)$ & $1(5.9)$ \\
Toxascaris leonina & $1(3.2)$ & $1(7.1)$ & $0(0)$ \\
Dipylidium caninum & $2(6.5)$ & $2(14.3)$ & $0(0)$ \\
Negative & $7(22.6)$ & $1(7.1)$ & $6(35.3)$ \\
\hline Total & 31 & 14 & 17 \\
\hline
\end{tabular}

Table 2. Young dogs with overall species prevalence and prevalence per sex

\begin{tabular}{lccc}
\hline \multicolumn{1}{c}{ Species } & $\begin{array}{c}\text { Prevalence } \text { - total } \\
{[\%]}\end{array}$ & $\begin{array}{c}\text { Male } \\
{[\%]}\end{array}$ & $\begin{array}{c}\text { Female } \\
{[\%]}\end{array}$ \\
\hline Family Ancylostomatidae & $7(70)$ & $2(66.7)$ & $5(71.4)$ \\
Isospora canis & $1(10)$ & $1(33.3)$ & $0(0)$ \\
Toxascaris leonina & $0(0)$ & $0(0)$ & $0(0)$ \\
Dipylidium caninum & $0(0)$ & $0(0)$ & $0(0)$ \\
Negative & $2(20)$ & $0(0)$ & $2(28.6)$ \\
\hline Total & 10 & 3 & 7 \\
\hline
\end{tabular}

Table 3. Total prevalence of endoparasites in dogs

\begin{tabular}{lc}
\hline \multicolumn{1}{c}{ Species } & $\begin{array}{c}\text { Total prevalence } \\
{[\%]}\end{array}$ \\
\hline Negative & $9(22.0)$ \\
Family Ancylostomatidae & $27(65.9)$ \\
Dipylidium caninum & $2(4.9)$ \\
Isospora canis & $4(9.8)$ \\
Toxascaris leonina & $1(2.4)$ \\
\hline \multicolumn{2}{c}{ Mixed infections } \\
\hline $\begin{array}{l}\text { Ancylostomatidae }+ \\
\text { Dipylidium caninum } \\
\text { Ancylostomatidae }+ \\
\text { Isospora canis }\end{array}$ \\
\hline
\end{tabular}

cysts of Isospora canis. By far the most prevalent parasite were species from the family Ancylostomatidae, where the highest prevalence $(67.7 \%)$ were noted. Table 1 shows the prevalence of the parasite species in the 31 adult samples examined. Isospora canis had an overall prevalence of $9.7 \%$. Toxascaris leonina and Dipylidium caninum were not found in the adult females; however in the adult males. D. caninum was found at a $14.3 \%$ prevalence and Toxascaris leonina at a $7.1 \%$ prevalence. Overall $22.6 \%$ of the dogs were negative with many more females (6 cases) being negative than the males ( 1 case).

The young also displayed a population sample largely infected with the family Ancylostomatidae (70 \%) (Table 2). More females (7) were found for sampling than males (3) with the overall sample size of 10 being lower than that of the adults which had 31 samples. There were no positive cases for T. leonina or D. caninum with just one young male being found to be infected with Isospora canis.

Table 3 below shows that there was a $78 \%$ chance of a dog from our sampling region testing positive for a gastrointestinal parasite. Within these positive dogs there was a $66 \%$ chance that the parasite belonged to the family Ancylostomatidae. Furthermore, species from the family Ancylostomatidae were involved in all the co-infections with D. caninum and I.canis. D.caninum, I. canis and T.leonina had a fairly low prevalence, with I.canis being the next most common after the family Ancylostomatidae, followed by D. caninum and T.leonina. 
There were no co-infections found in the young dogs. There were three cases of co-infections which we found in 2 males and in 1 female.

\section{DISCUSSION}

Nonaka et al. conducted a similar study in other regions of Zambia [7] and also found that the eggs of the Ancylostomatidae family were by far the most abundant in their study with $43.3 \%$ on average. Our study region showed an even higher prevalence of $66 \%$. As only the classical faecal egg examination was undertaken in this study, it was not possible to distinguish between the morphologically similar eggs of the Ancylostomatidae family. A second study conducted by Islam and Chizyuka [4] further North in Zambia found the species to be Ancylostoma caninum and Ancylostoma braziliense. They found a much lower prevalence of Ancylostoma spp. eggs (10\%) and other helminths; however, they acknowledged that there selection of dogs were those from a better cared for and more restricted background than those used in other studies [4].

All of the parasite species detected in our study were also found in other regions of Zambia by other authors, however, their studies exhibited a larger species richness [4, 7]. They detected the following additional parasites: family Teniidae, Toxocara canis, Diphyllobothrium spp., Spirocera lupi, Echinococcus granulosus, Sarcocystis spp., Physaloptera spp., Capillaria spp., Mesocestoides spp., Ascaris spp., Trichuris vulpis, and Schistosoma mansoni. The increased richness may be as a result of their more advance detection techniques including coproantigen ELISA for Echinococcus and PCR, as well as a much larger sample size of 540 dogs.

The high prevalence of the family Ancylostomatidae is of particularly significant due to its zoonotic potential. Man is an accidental host and larvae cannot reach full maturity within them; however Ancylostoma caninum can cause eosinophilic enteritis and A. braziliense which is the primary cause of cutaneous larva migrans [9]. The possible reasons for its high prevalence may be due to the multiple modes of transmission including direct ingestion, per cutaneous, via paratenic hosts such as rodents and in the case of $A$. caninum, the additional possibility of transmammary, as well as lactogenic transmission [8]. Transmammary and lactogenic transmission may also help explain its almost equally high prevalence in the young (70\%) as well as the adults
(67.7 \%). Species of the family Ancylostomatidae are prolific egg layers with the potential to pass millions of eggs into the environment daily [9] and as all dogs in this study freely roam over large territories, there is a very high chance of them obtaining an infection.

Infectious concentrations of the family Ancylostomatidae eggs were higher in the adults with $60 \%$ of adults having a medium concentration of infection in the samples which was $30 \%$ higher than that of the young dogs. Furthermore, $25 \%$ of the adults were found to have a high intensity of infection, whereas only $10 \%$ of the young dogs had similar results. This may be as a consequence of the dogs having an increased chance of exposure of obtaining an infection orally or per-cutaneously over time.

When comparing adult males and females for the family Ancylostomatidae, the two tailed P-value of 0.369 indicates that there is no significant difference between the sexes. Statistical analysis in the other categories were not calculated as the expected values from the null hypothesis fall below 5 making it an inadequate statistical test.

Dipylidium caninum was not detected in the young but it was found in $4.9 \%$ of the adults, Islam and Chizyu$\mathrm{ka}$ [4] found a much higher prevalence of $25 \%$, however Non aka et al. [7] found a more similar prevalence (2.2\%) to our results. It seems surprising that the infection rate was not higher considering that dogs had never been given anti-ectoparasitic treatment and most of them were visibly infected with fleas, which are intermediate host of $D$. caninum [1]. D. caninum, I. canis and T. leonina are not transmitted lactogenically or prenatally $[9,10]$, which would contribute to their lower prevalence in younger dogs.

\section{CONCLUSIONS}

It was found that the Mbabala region in the SouthWest of Zambia was no exception to the large prevalence of gastrointestinal endoparasites in tropical and subtropical regions of the world [10]. Eggs of the family Ancylostomatidae were largely prevalent with the young and adult rural dogs standing a very high chance of infection. The chance of getting infected with Isospora canis, Dipyllidium caninum, and Toxascaris leonina infections were much lower with adults having a higher risk of obtaining an infection than the young. Co-infections were not common but were detected in 3 adult dogs. 
Education on the zoonotic risks and the need for antihelminthic drugs was minimal and therefore needs to be encouraged. However, due to the fact that the vast majority of homes in these rural areas live in abject poverty, the drugs required are completely unaffordable to the owners, thus emphasizing the need to develop a program of free treatments. It is not so much a question of willingness but rather affordability.

\section{ACKNOWLEDGMENTS}

The research was supported by the project VEGA No. $1 / 0455 / 15$.

\section{REFERENCES}

1. Ballweber, L.R., 2001: Veterinary Parasitology. Butterworth-Heinemann. Woburn, $324 \mathrm{pp}$.

2. D-maps. http://www.d-maps.com/m/africa/zambie/zambie59.gif. Updated 12/3/2016. Accessed 12/3/2016.

3. Fang, F., Li, J., Huang, T., Guilot, J., Huang, W., 2015: Zoonotic helminths parasites in the digestive tract of feral dogs and cats in Guangxi, China. BMC Veterinary Research, 11, 211, $1-5$.

4. Islam, A. W.M.S., Chizyuka, H.G.B., 1983: Prevalence of helminth parasites of dogs in Lusaka, Zambia. Tropical Animal Health Production, 15, 234-326.
5. Kanno, H., Sakurai, T., Shinjo, H., Miyazaki, H., Ishimoto, Y., Saeki, T. et al., 2013: Indigenous Climate Information and Modern Meteorological Records in Sinazongwe District, Southern Province, Zambia. Japan Agricultural Research Quarterly, 47, 191-201.

6. Lynne, S. G., Garcia, M.S., Bruckner, D.A., 1997: Diagnostic Medical Parasitology, Diagnostic procedures. 3rd edn., ASM press Washington, 593-608.

7. Nonaka, N., Nakamura, S., Inoue, T., Oku, Y., Katakura, K., Matsumoto, J. et al., 2011: Coprological survey of alimentary tract parasites in dogs from Zambia and evaluation of a coproantigen assay for canine echinococcosis. Annals of Tropical Medicine and Parasitology, 105, 7, 521-530.

8. Sichingabula, H.M., 1998: Water Resources Variability in Africa During the XXth Century. International Association of Hydrological Sciences 1998. Oxfordshire. 129 pp.

9. Taylor, M.A., Coop, R.L., Wall, R.L., 2007: Veterinary Parasitology. 3rd edn., Blackwell Publishing, Oxford, 856 p.

10. Urquhart, G.M., Armour, J., Duncan, J.L., Dunn, A. M., Jennings, F. W., 1996: Veterinary Parasitology. Blackwell Publishing, Glasgow, 286 pp.

11. Zewdu, E., Semahegn, Y., Mekibib, B., 2010: Prevalence of helminth parasites of dogs and owners awareness about zoonotic parasites in Ambo town, central Ethiopia. Ethiop. Vet. J., 14, $17-30$.

Selected paper from the 59th STUDENT SCIENTIFIC CONFERENCE, Section III - Food hygiene and the environment, held at the University of Veterinary Medicine and Pharmacy in Košice, SR, on April 6, 2016. 